\title{
Power Control of a Wind Energy Conversion System based on a Doubly Fed Induction Generator
}

\author{
Bouchaib Rached \\ bouchaib.rached@gmail.com
}

\author{
Mustapha Elharoussi \\ m.elharoussi@gmail.com
}

\author{
Elhassane Abdelmounim \\ hassan.abdelmounim@hotmail.fr
}

ASTI Laboratory, FST Hassan I University in Settat, Morocco

\begin{abstract}
Over the last years, there has been a strong penetration of renewable energy resources into the power supply network. Wind energy generation has played and will continue to play a very important role in this area for the coming years.

Currently, the wind using a doubly-fed induction generator «DFIG» are the more used for the production of the electric energy. Our work consists of modelling of a chain of conversion of the wind energy where the doubly-fed induction generator operates at variable speed. thereafter, we consider the regulating of the active and reactive powers in order to ensure optimum operation.

To this effect, we have established a vectorial control to ensure a decoupling between the electromechanical variables. The command is developed and validated using Matlab/Simulink in order to analyze by simulation the behavior of the chain in the fields of possible function.
\end{abstract}

Keywords: Wind energy conversion system (WECS); Vector control; Doubly Fed Induction Generator (DFIG).

\section{Introduction}

To increase the operational speed range of wind turbines and eliminate soft starter and gridside reactive power compensator, a variable speed turbines based on doubly fed induction generator (DFIG) were developed. The configuration of Wind Energy Conversion System (WECS) using a DFIG and power electronic converter is shown in Figure 1 [1][2]. As the name implies, power from the doubly fed induction generator is fed to the grid through both stator and rotor windings.

The power converter is usually made of two-level voltage source converters connected in a back to back configuration. The machine-side converter, also called a rotor-side converter (RSC), controls the generator torque/speed or active/reactive power, whereas the grid side converter (GSC) controls the net DC-bus voltage[3][4] .

The advantages of the DFIG are that rotor power allows variable speed, high starting torque capability, and flexible reactive power control. 
This work presents a control chain conversion based on a (D.F.I.G). To improve the transient and steady state performance and the power factor of generation, a stator flux oriented vector control scheme is used in this work. The vector control structure employs conventional PI controllers for the decoupled control of the stator side active and reactive power. The whole system is modeled and simulated using Matlab/Simulink and the results are analyzed.

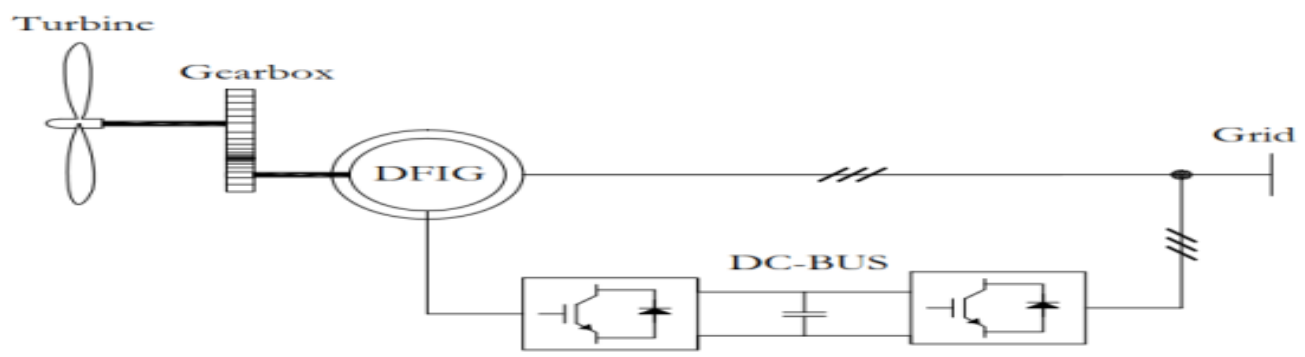

Fig. 1. Variable speed wind turbine.

\section{WIND TURBINE MODELING}

The power contained in the wind is given by the kinetic energy of the flowing equation [5][2][6]:

$$
P_{\text {aero }}=\frac{1}{2} \cdot C_{P}(\beta, \lambda) \cdot \rho \cdot \pi \cdot R_{\text {Pale }}^{2} \cdot V_{\text {wind }}^{3}
$$

Where $\rho$ is the air density $\left(\mathrm{kg} / \mathrm{m}^{3}\right), R_{\text {Pale }}$ is the blade radius $(\mathrm{m}), V_{\text {wind }}$ is the wind speed, $C_{P}(\beta, \lambda)$ is the turbine power coefficient, and $\lambda$ is the tip speed ratio, which is defined by:

$$
\lambda=\frac{\Omega_{t} \cdot R_{\text {Pale }}}{V_{\text {wind }}}
$$

Where $\Omega_{t}$ is the Rotational speed of the turbine.

The aerodynamic torque is given by:

$$
T_{\text {aero }}=\frac{P_{\text {aero }}}{\Omega_{t}}=\frac{1}{2} \cdot C_{P}(\lambda, \beta) \cdot \rho \cdot S \cdot \frac{V_{\text {wind }}^{3}}{\Omega_{t}}
$$

Where $\mathrm{S}$ is the area swept by the pales of the turbine.

\section{DFIG MODELING AND POWER CONTROL}

\subsection{DFIG model}

For a doubly fed induction machine, the Concordia and Park transformation's application to the traditional a,b,c model allows to write a dynamic model in a $\mathrm{d}$-q reference frame as follows by [7][8][9]: 
Electrical equations

$$
\left\{\begin{array}{c}
V_{S d}=R_{S} I_{S d}+\frac{d}{d t} \Phi_{S d}-\omega_{S} \Phi_{S q} \\
V_{S q}=R_{S} I_{S q}+\frac{d}{d t} \Phi_{S q}+\omega_{S} \Phi_{S d} \\
V_{r d}=R_{r} I_{r d}+\frac{d}{d t} \Phi_{r d}-\omega_{r} \Phi_{r q} \\
V_{r q}=R_{r} I_{r q}+\frac{d}{d t} \Phi_{r q}+\omega_{r} \Phi_{r d}
\end{array}\right.
$$

Stator and rotor flux equations

$$
\left\{\begin{array}{l}
\Phi_{S d}=L_{S} I_{S d}+M I_{r d} \\
\Phi_{S q}=L_{S} I_{S q}+M I_{r q} \\
\Phi_{r d}=L_{r} I_{r d}+M I_{S d} \\
\Phi_{r q}=L_{r} I_{r q}+M I_{s q}
\end{array}\right.
$$

Stator and rotor active and reactive powers

$$
\begin{aligned}
& \left\{\begin{array}{l}
P_{S}=v_{S d} \cdot i_{S d}+v_{S q} \cdot i_{S q} \\
Q_{S}=v_{S q} \cdot i_{S d}-v_{S d} \cdot i_{S q}
\end{array}\right. \\
& \left\{\begin{array}{l}
P_{r}=v_{r d} \cdot i_{r d}+v_{r q} \cdot i_{r q} \\
Q_{r}=v_{r q} \cdot i_{r d}-v_{r d} \cdot i_{r q}
\end{array}\right.
\end{aligned}
$$

The electromagnetic torque

$$
T_{e m}=p M\left(I_{r d} I_{S q}-I_{r q} I_{S d}\right)
$$

\subsection{Establishment of the Control Strategy}

Through aligning the direct axis of the reference frame along the stator flux vector position (FOC) $[10][11][12]$, the following relationships can be derived from Eq. (5):

$$
\begin{gathered}
\phi_{S q}=0 \Leftrightarrow \phi_{S}=\phi_{S d} \\
\left\{\begin{array}{c}
V_{S d}=0 \\
V_{S q}=\omega_{S} \Phi_{S d}=V_{s}
\end{array}\right. \\
\left\{\begin{array}{c}
\Phi_{S d}=L_{S} I_{S d}+M I_{r d} \\
\Phi_{S q}=L_{S} I_{S q}+M I_{r q}=0
\end{array}\right.
\end{gathered}
$$


The adaptation of the relations (6), (7), and (11) to the chosen system of axes and the simplifying hypotheses considered in our case gives:

$$
\begin{gathered}
P_{S}=-V_{S} \frac{M}{L_{S}} I_{r q} \\
Q_{S}=\frac{V_{S} \Phi_{S}}{L_{S}}-\frac{V_{S} M}{L_{S}} I_{r d} \\
\left\{\begin{array}{l}
P_{r}=g V_{S} \frac{M}{L_{S}} I_{r q} \\
Q_{r}=g \frac{V_{S} M}{L_{S}} I_{r d}
\end{array}\right.
\end{gathered}
$$

Therefore, the $\mathrm{d}$ and $\mathrm{q}$ axis components of the rotor current have to be manipulated to control the stator reactive and active power respectively. The current control loop is based on the rotor circuit equations of the DFIG.

$$
\left\{\begin{array}{c}
v_{r d}=R_{r} I_{r d}-L_{r} \omega_{r} \sigma I_{r q}+L_{r} \sigma \frac{d I_{r d}}{d t} \\
v_{r q}=R_{r} I_{r q}+L_{r} \omega_{r} \sigma I_{r d}+\frac{M \omega_{r}}{L_{s}} \Phi_{s d}+L_{r} \sigma \frac{d I_{r q}}{d t}
\end{array}\right.
$$

The control variables Vdr and Vqr of the rotor voltage can be obtained from eq.(14). The influence of the cross-coupling between the $d$-q axis components of rotor current on system performance is small, which can be eliminated by adopting some control law. The model of the vector control of the rotor-side converter obtained from the above analysis is shown in Fig. 2.

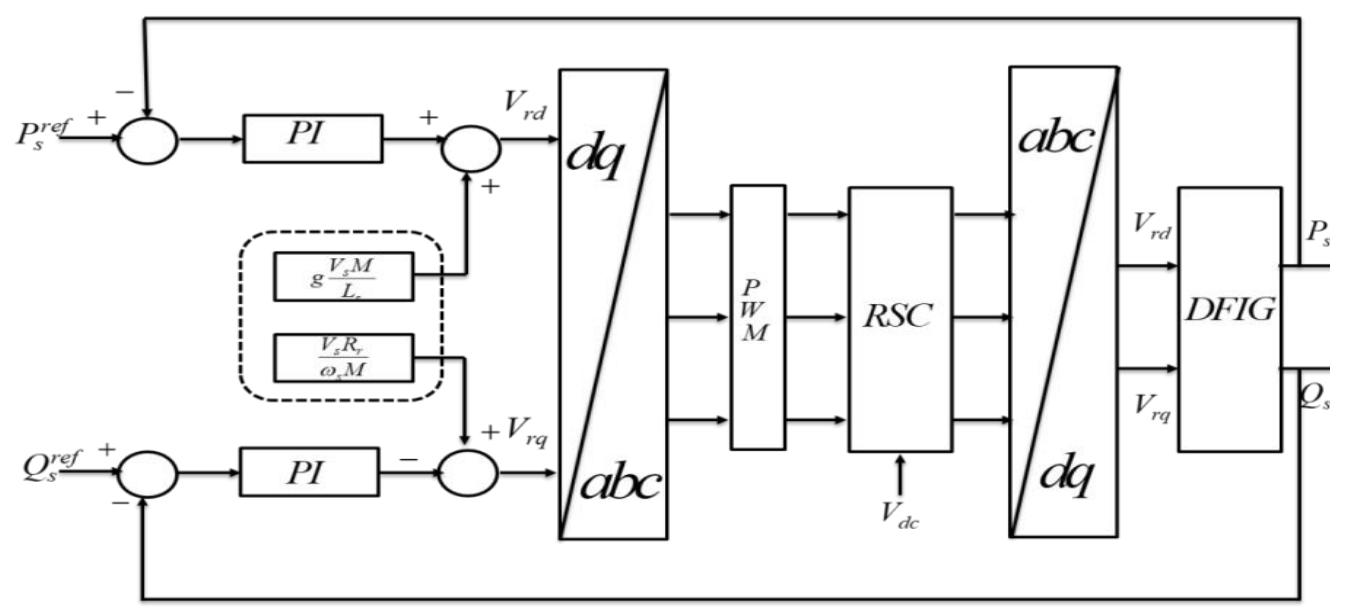

Fig. 2. Block Diagram of vector control design 


\section{SIMULATION RESULTS}

The DFIG connected directly to the grid through the stator, and its speed is controlled via a back-to-back PWM converter. The parameters of the DFIG are given in Table 1.

Table 1. Detailed parameters of the DFIG.

\begin{tabular}{|l|l|}
\hline Rated power & $1.5 \mathrm{MW}$ \\
\hline$\rho$ & $1.225 \mathrm{Kg} / \mathrm{m} 3$ \\
\hline Blade Radius R & $35.25 \mathrm{~m}$ \\
\hline Stator resistance RS & $0.012 \Omega$ \\
\hline Rotor resistance $\mathrm{Rr}$ & $0.021 \Omega$ \\
\hline Stator inductance $\mathrm{LS}$ & $0.0137 \mathrm{H}$ \\
\hline Rotor inductance $\mathrm{Lr}$ & $0.0136 \mathrm{H}$ \\
\hline Mutual inductance $\mathrm{M}$ & $0.0135 \mathrm{H}$ \\
\hline Moment of inertia $\mathrm{J}$ & $0.175 \mathrm{~kg} \cdot \mathrm{m}^{2}$ \\
\hline Damping coefficient $\mathrm{f}$ & $0.0024 \mathrm{~N} / \mathrm{rd} / \mathrm{s}$ \\
\hline Number of pole pairs $\mathrm{p}$ & 2 \\
\hline$C$ & $2.2 \mathrm{mF}$ \\
\hline
\end{tabular}

Figures 3 and 4 illustrate respectively the stator active power and reactive power. We can see the robustness of the power control of the DFIG. Figures 5 and 6 show the rotor and stator currents waveforms. The frequency of these current, vary according to the slip s.

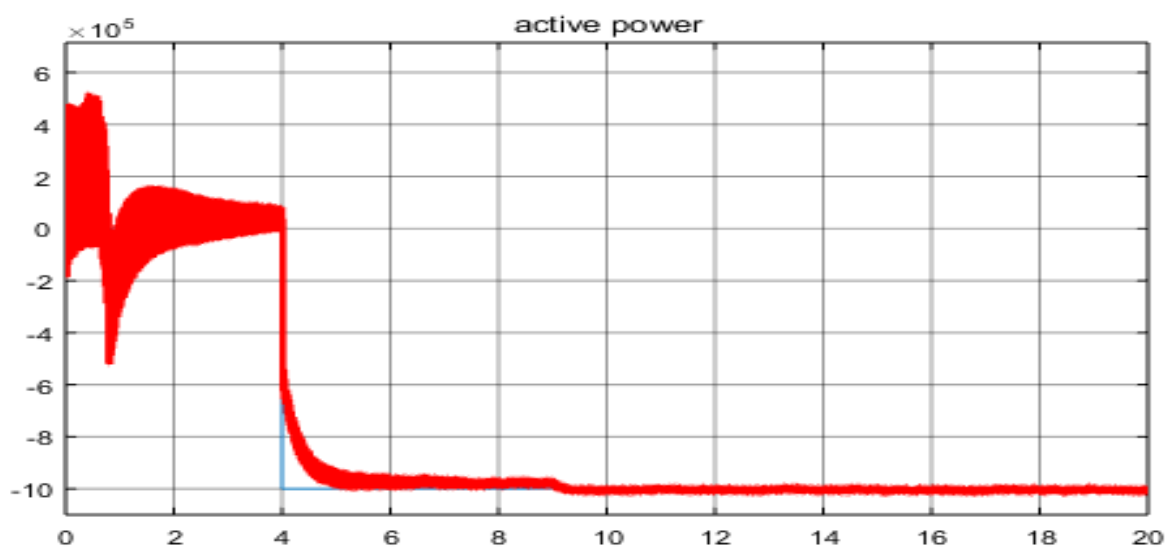

Fig. 3. Stator active power response 


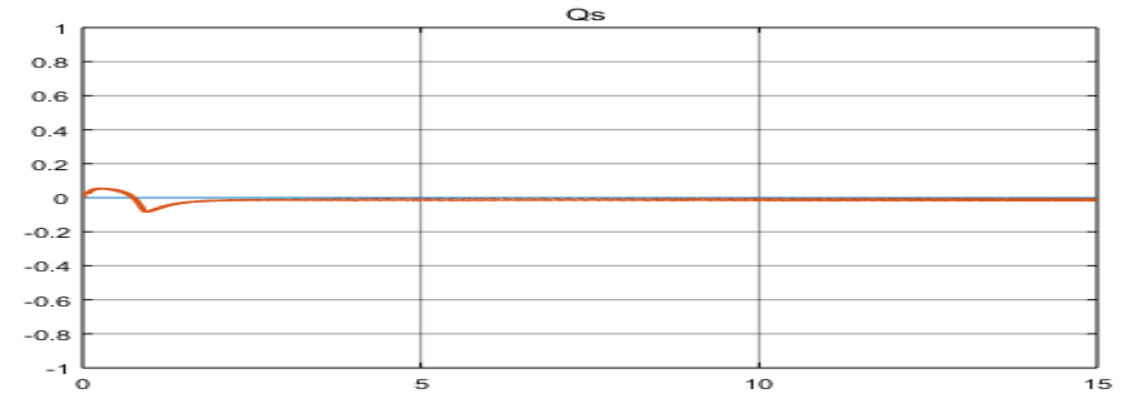

Fig. 4. Stator reactive power response

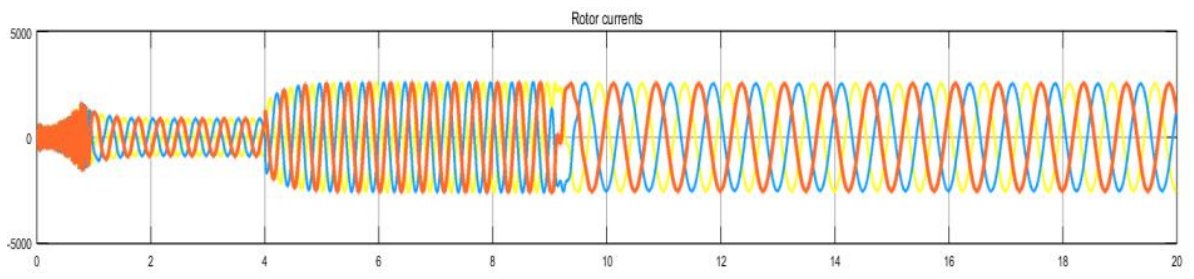

Fig. 5. rotor currents response

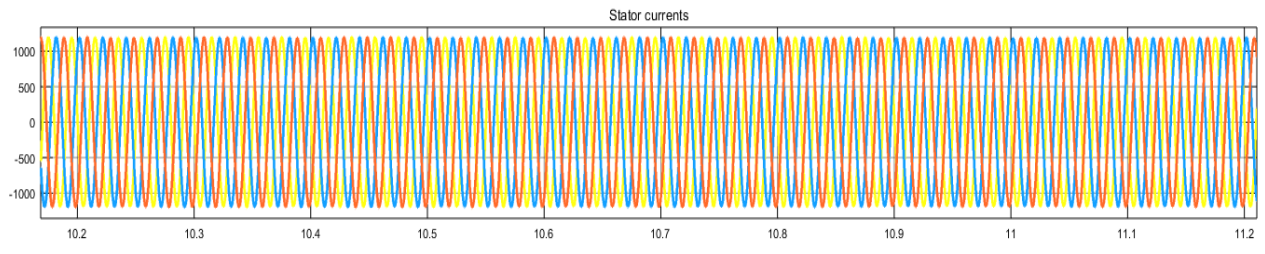

Fig. 6. Stator currents response

The active power of DFIG follows the variation of the setpoint and the reactive power is mainted to zero, which signified the reactive power output is not affected. The simulation result indicates that the active and reactive power decoupled control is achieved and the performance is good. According to the results found in literature[13][14], which show the results of the implementation of PI controllers on wind power systems, and by observing the previous results, we see that the controller presented in this paper has a fewer oscillations during setpoint changes, and the peaks of disturbances are much less significant.

\section{CONCLUSION}

The control of the doubly fed induction generator, used in variable-speed wind power generation, was considered. And a control structure using standard proportional integral PI controller and a field-oriented control strategy is described and simulated.

The simulation result indicates that the active and reactive power decoupled control is achieved and the performance is good. 


\section{References}

[1] I. Munteanu, Optimal control of wind energy systems : towards a global approach. Springer, 2008.

[2] G. Abad, Doubly fed induction machine: modeling and control for wind energy generation applications. Wiley-Blackwell Pub, 2011.

[3] J. A. Baroudi, V. Dinavahi, and A. M. Knight, "A review of power converter topologies for wind generators," International Journal of Renewable Energy, vol. 32, no. 14, pp. 2369-2385, 2007.

[4] Z. Zhu and J. Hu, "Electrical machines and power-electronic systems for high-power wind energy generation applications: Part I - market penetration, current technology and advanced machine systems,"COMPEL:The International Journal for Computation and Mathematics in Electrical and Electronic Engineering, vol. 32, no. 1, pp. 7-33, 2013.

[5] P. M. M. Bongers, "Modeling and Identification of Flexible Wind Turbines and A Factorizational Approach to Robust Control Design." 1994.

[6] B. Beltran et al., "Sliding Mode Power Control of Variable Speed Wind Energy Conversion Systems To cite this version: Sliding Mode Power Control of Variable Speed Wind Energy Conversion Systems," 2010.

[7] G. S. Kaloi, J. Wang, and M. H. Baloch, "Active and reactive power control of the doubly fed induction generator based on wind energy conversion system," Energy Reports, vol. 2, pp. 194 200, Nov. 2016.

[8] C. Hamon, K. Elkington, and M. Ghandhari, "Doubly-fed induction generator modeling and control in DigSilent PowerFactory," in 2010 International Conference on Power System Technology, 2010, pp. 1-7.

[9] A. Boyette, "Contrôle-commande d'un générateur asynchrone à double alimentation avec système de stockage pour la production éolienne," Dec. 2006.

[10] S. Khojet El Khil, I. Slama-Belkhodja, M. Pietrzak-David, and B. de Fornel, "Power distribution law in a Doubly Fed Induction Machine,” Math. Comput. Simul., vol. 71, no. 4-6, pp. 360-368, Jun. 2006.

[11] M. Elhaissouf, E. Lotfi, B. Rached, M. Elharoussi, and A. Barazzouk, "DSP Implementation in the Loop of the Indirect Rotor Field Orientation control for the Three-Phase Asynchronous Machine," in Proceedings of the 2nd International Conference on Computing and Wireless Communication Systems - ICCWCS'17, 2017, pp. 1-7.

[12] E. Lotfi, B. Rached, M. Elhaissouf, M. Elharoussi, and E. Abdelmounim, "DSP Implementation in the Loop of the Vector Control Drive of a Permanent Magnet Synchronous Machine," in Proceedings of the 2nd International Conference on Computing and Wireless Communication Systems - ICCWCS'17, 2017, pp. 1-7.

[13] A. Dekhane, S. Lekhchine, T. Bahi, S. Ghoudelbourg, and H. Merabet, "DFIG modeling and control in a wind energy conversion system," 2012 1st Int. Conf. Renew. Energies Veh. Technol. REVET 2012, pp. 287-292, 2012.

[14] S. P. Uma and S. Manikandan, "Control technique for variable speed wind turbine using PI controller," in 2013 IEEE International Conference ON Emerging Trends in Computing, Communication and Nanotechnology (ICECCN), 2013, pp. 640-643. 